\title{
Comparison of stress distribution around implants with three different attachments in overdenture supported by four maxillary implants using finite element analysis method
}

\author{
Asadallah Ahmadzadeh ${ }^{1}$ and Ahmad Teimouri2* \\ ${ }^{1}$ Assistant Professor, Department of Prosthodontics, School of Dental Medicine, Ahvaz Jundishapur \\ University of Medical Sciences Ahvaz Iran \\ ${ }^{2}$ Assistant Resident, Department of Prosthodontics, School of Dental Medicine, Ahvaz Jundishapur University \\ of Medical Sciences Ahvaz Iran
}

\begin{abstract}
As a general rule, the purpose of treatment planning should be minimization and evenly distribution of mechanical stress in the adjacent implant and bone system. Various experimental studies have examined the distribution of stress in the implant supporting bones, thus avoiding the dangers involved. But there is still controversy about biomechanical effects and stress distribution in different attachment designs. The purpose of this study was to compare the distribution of stress around the implant with three different attachments in overdenture based on four maxillary implants using finite element analysis method (FEA). In this experimental study, using the FEA method, a 3D model of maxilla, implant, attachment components and overdenture was first prepared and then, using the ANSYS finite element software, the components of the model were superimposed on each other so that it can act as a component integrated with different materials. Implants are located in the anterior and posterior parts of the maxilla, with two implants placed in the two sides of the canine, one in the left central position and the other in the right second premolar. These implants were attached to the overdenture using three bar-clip, ball, and locator attachment designs. The $100 \mathrm{~N}$ force used in this study and imposed vertically to the tooth 6 unilaterally and bilaterally and the stress level was investigated in each design. Among the three different designs examined, the highest stress was observed in the vertical force (22.87 $\mathrm{MPa})$ imposed on the implant in the right second premolar on the right overdenture supported by the locator implant. In the second place, the highest stress was observed on the Ball-retained overdenture in the right side force, imposed on the implant in the right second premolar corresponding to $12.88 \mathrm{MPa}$. The least stress among these three designs was observed in the bar-clip-retained overdenture design, the maximum stress on which is in the vertical force imposed on the right side to the right second premolar implant at the size of 7.486MPa. Bar-clip-retained overdenture with the lowest stress caused by the $100 \mathrm{~N}$ force is the most appropriate design in the present study.
\end{abstract}

KEY WORDS: FINITE ELEMENT METHOD; STRESS TEST; BAR-CLIP ATTACHMENT; BALL ATTACHMENT; LOCATOR ATTACHMENT; OVERDENTURE

ARTICLE INFORMATION:

*Corresponding Author:Dr.ahmad2013@yahoo.com

Received $12^{\text {th }}$ July, 2017

Accepted after revision $22^{\text {nd }}$ Sep, 2017

BBRC Print ISSN: 0974-6455

Online ISSN: 2321-4007 CODEN: USA BBRCBA

Thomson Reuters ISI ESC and Crossref Indexed Journal

WAAS Journal Score 2017: 4.31 Cosmos IF: 4.006

${ }^{-}$A Society of Science and Nature Publication, 2017. All rights reserved.

Online Contents Available at: http//www.bbrc.in/

DOI: $10.21786 / \mathrm{bbrc} / 10.3 / 19$ 


\section{INTRODUCTION}

Considering the aging of people in communities and consequently the increase in complete edentulousness, today edentulousness has become a public health problem. Unfortunately, in Iran, edentulousness is not seen only in the elderly and many young people also suffer from complete edentulousness for a variety of reasons, including systemic diseases, non-compliance with oral and dental care, and absence of periodic visit to the dentist. Edentulousness can reduce the quality of life of patients both physically and psychologically. Recent studies have shown that tooth loss can affect the intake and absorption of nutrients due to reduced chewing ability, and increase the risk of multiple diseases. For this reason, dental implants are used to improve the chewing efficacy in complete edentulous patients and have improved the quality of life of these patients to an optimum level, (MacEntee et al 2003, Abnet et al., 2005, Semba et al 2006, Goiato et al 2008, Pennington et al 2012, Cunha et al 2013 Cakir et al 2014, Dezhdar et al 2017 and Geerts 2017).

The treatment that is predominantly performed for edentulous patients is the use of complete denture hands. From a public health perspective, although this treatment is a simple and inexpensive treatment, it cannot, be a general remedy for all patients. One of the main problems in edentulousness patients is their low satisfaction in denture use. The main reason for this discontent is poor compliance, inadequate collision, ulceration and pain (Zarb et al 2004). Considering the problems mentioned for ordinary complete dentures, a rational solution must be sought to the problems. Two types of treatment are widely used for these patients: there are fixed implant supported prostheses and implant-dependent overdenture that are widely used for complete edentulous patients (Dias et al 2013) and the use of any of these treatments depends on the patient's characteristics and conditions, including the amount of bone remaining, intervertebral space, oral hygiene, cost, and patient satisfaction (Zafiropoulos et al 2010).

Fixed implant-based prostheses may be one of the best ways to treat edentulousness and are implemented in case of sufficient bone and mandibular space (Chee et al 2006). More implants are usually needed to support a fixed prosthesis than an overdenture (Payne et al 2009). Since it is sometimes impossible to use a large number of implants for the patient, this issue limits the use of fixed prostheses (Chee et al 2006). Other constraints on the use of fixed prostheses is the loss of facial beauty due to the lack of lip support and soft tissue face, lack of access to hygiene, multiple and high cost surgical procedures (Vogel 2007). Using overdentures has greatly resolved the problems associated with the use of fixed prosthe- sis. Implant-based overdenture is a moving prosthesis that is placed on smaller number of implants per jaw, and has excellent attachment and stability. Overdenture is a simple, cost-effective, durable, less invasive treatment and a successful treatment option for edentulous patients and its use has recently become very common (Assunção et al 2008). Implant-based overdenture has improved the function of implant therapy (Awad et al 2003) due to the benefits of physical and natural beauty, and is superior to conventional dentures in many cases (Sadowsky 2001). Different studies have shown that this type of treatment has improved general health and quality of life of patients (Awad et al 2003). So, although the patient wants a fixed implant-based prosthesis, (s) he tends to use overdenture. Implant-based overdentures are connected to the implant by an interstitial part called attachment, which allows the prosthesis to resist against displacement forces (Locker 1998).

Many attachments such as rods, buttons, and magnets, are used to support implant-dependent overdentures (Machado et al 2011). Clinical success and longevity of dental implants are affected by the distribution of stress transferred to the implant and surrounding bones (Jacques et al 2009). Also, the lack of sufficient biocompatibility between the implant and the surrounding bone can lead to implant failure (Berglundh et al 2002). Different attachment systems used in overdentures show different biomechanical characteristics and can be dangerous to implant supporting bones (Sadowsky 2007). Various experimental studies have examined the distribution of stress in the implant supporting bones, thus avoiding the dangers involved. But there is still controversy about biomechanical effects of stress distribution in different attachment designs (CHUN et al 2005) and (Baumeister 1978). Paying attention to the principles of biomechanics in implant-based prosthesis can provide a suitable treatment design for each patient and reduce the probability of functional problems or implant failure (Baumeister 1978). Different methods are used to evaluate the stress and strain in the bone around the implant, which can be used for photoelastic analysis, strain gauge, and finite element analysis.

Fine Element Analysis (FEA) is a precise method for evaluating the amount and pattern of stress distribution in dental structures which has many advantages over other methods. Precise geometric reconstruction of the structures involved in stresses acceptance and distribution, ability to accept and receive different simply, showing the procedure of internal stresses and other mechanical quantities, rapid and simple repeatability of the tests are among the benefits of this study method. FEA is a numerical and quantitative method for analyzing stress in complex structures. In this method, separate structural elements are connected through points 
or nodes. These components are created by dividing the primary structure into units of the proper shape. For each element, the physical properties are considered proportional to the simulated material (Powers 2006).

This method is also used in dental studies as an ideal method for preparing the correct tooth model and it's supporting structures in three dimensional form. This method can provide measurement of partial mechanical responses towards the difference in mechanical parameters and the evaluation of stress in dental materials and tissues at different levels (Motta et al 2006). Various studies, using the FEA method, have shown that stress distribution in maxillary and mandibular implant systems is significantly affected by various attachment designs (CHUN et al 2005). The maxillary implant supportedoverdentures are less predictable than mandibular overdentures, and there is controversy over the use of different designs and the number of implants used (Dudley 2014). One of the overdenture treatments in maxilla is the use of four implants, which has been studied in few studies. There are also few studies on maxillary overdenture than the mandibular one (Raghoebar et al 2014).

Some studies have shown that 4 or more than 4 maxillary implant-dependent overdentures are more stable and more durable than less than 4 implant-dependent overdentures (Raghoebar et al 2014). These implants can hold the overdenture with various attachments. Results of studies on the acceptance and use of various attachments showed that the bar and button attachments that have a good stability as well as locators that are newer, are at a higher level in terms of general acceptance and enjoy more clinical use (Büttel et al 2009) and (Lončar 2015). For this reason, these attachments will be used in a four-implant design to measure stress in the present study. The present study uses a FEA method to simulate the structure of various overdenture designs based on four maxillary implants, to investigate the distribution of Von Mises stress in the surface of all attachments and implant supporting bones so that the most suitable solution for the treatment is identified.

\section{MATERIAL AND METHODS}

The present study is an experimental study in which the distribution of stress is investigated and compared in 4 maxillary implant-dependent overdentures by FEA method. In this study, the CBCT-Scan (NewTom VGi; Finland) of a 30-year-old patient that was available in the radiology department of Ahwaz Dental Faculty was used to prepare the Maxilla model. Maxilla data were imported to the Mimics ver. 8.1.1 for digitalization of images. After transferring CBCT-Scan data to the Mimics software, other changes were made to this data, which included deleting the patient's tooth data from the initial data. The entire maxilla structure and root site of the teeth was reconstructed with cortical bone and $2 \mathrm{~mm}$ soft gum tissue was considered on it. The maxillary bone structure was considered isotopic and homogeneous, while the elasticity coefficient was linearly assumed. The overdenture was constructed on the maxilla model that was obtained by a $3 \mathrm{D}$ printer of the existing model. It is essential to accurately measuring the implant for implant modeling. Hence, one specimen of SPI implant (Thommen Medical, Element, Switzerland) with a diameter of $4 \times 12.5 \mathrm{~mm}$ was measured by the Coordinate Measuring Machine (CMM; MitutoyoAmerica Corporation) and the dimensions required for modeling were used in solid works 2014. In this study, Ball, Bar-clip, Locator (ThommenMedical, Switzerland) attachments were used. Overdenture and attachments were initially measured by CMM and turned into digital images. The output file of the Mimics software was imported to the modeling software called Solid Works (SolidWorks ${ }^{\circledR}$ Office Premium 2007 SP, Corporation, Concord, MA, USA) to turn into a geometric model. Geometric modeling in Solid Work software was performed automatically based on the surface detail specified by the user. In the above model, implants were placed in the right second premolar, left and right canine and left central regions. One 4-mm long locator with housing with a diameter of $3.6 \mathrm{~mm}$ and a height of $2.3 \mathrm{~mm}$ was modeled. Also, ball with a width of 2.2 and a height of $4.3 \mathrm{~mm}$ and bar-clip with width and height of 2.2 and $3 \mathrm{~mm}$ respectively were modeled. In the Bar design, the abutment pattern was used and the outside part of the implant had height of $5.5 \mathrm{~mm}$.

The next step in FEA modeling is to apply appropriate boundary conditions and loading. For this purpose, the geometric model was imported to ABAQUS / Standard software (Version 6.14/1, Pawtucket, IR) for finite analysis. ANSYS software was used to implement FEA modeling. The elements used in this study included SOLID187, CONTA174 and TARGE170, the first of which was used to generate the grid in the geometric model components and the latter two elements for the attachments. In the loading stage, the $100 \mathrm{~N}$ static forces were applied vertically to the center of the first molar center and the stress distribution was demonstrated on the surface of all implant supporting attachments and bones based on computer graphic forms.

\section{RESULTS AND DISCUSSION}

Among the three different designs examined, the highest stress was observed in the vertical force $(22.87$ $\mathrm{MPa}$ ) imposed on the implant in the right second premolar on the right overdenture supported by the locator implant. In the second place, the highest stress was 


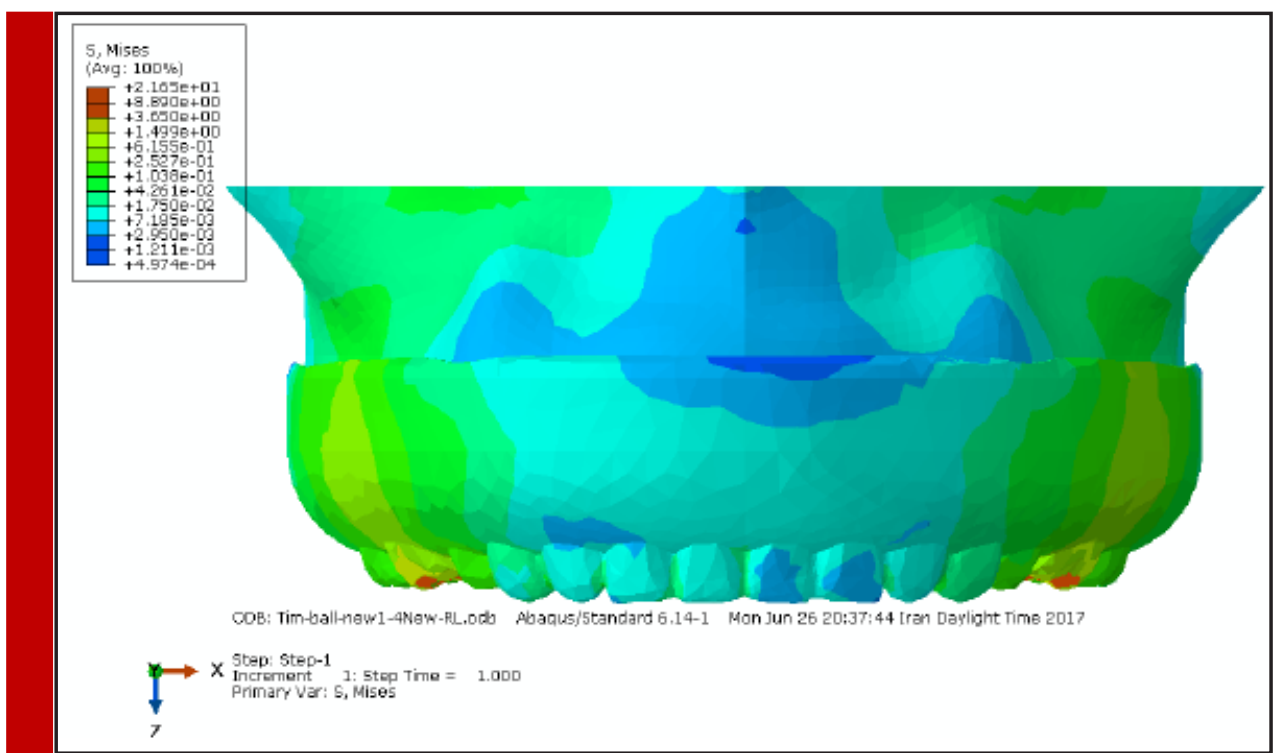

FIGURE 1. Distribution of stress caused by the bilateral force in ball attachment-based overdenture

observed on the Ball-retained overdenture in the right side force, imposed on the implant in the right second premolar corresponding to $12.88 \mathrm{MPa}$. The least stress among these three designs was observed in the barclip-retained overdenture design, the maximum stress on which is in the vertical force imposed on the right side to the right second premolar implant at the size of 7.486MPa. In the working side of the bone, the most stress was induced to the nearest implant of the same side. The results for the highest levels of stress in dense and sponge bones did not reach the final bone resorption in any of the treatment plans (Figures 1 to 4). Therefore, it can be concluded that overdenture based on the bar-clip implant with the least stress produced by the $100 \mathrm{~N}$ force, is the most suitable design, and the ball design has the least stress and is suitable in the second place (Tables 1 to 6).

In the working side of the bone, the most stress was imposed to the nearest implant of the same side. The results for the highest levels of stress in dense and

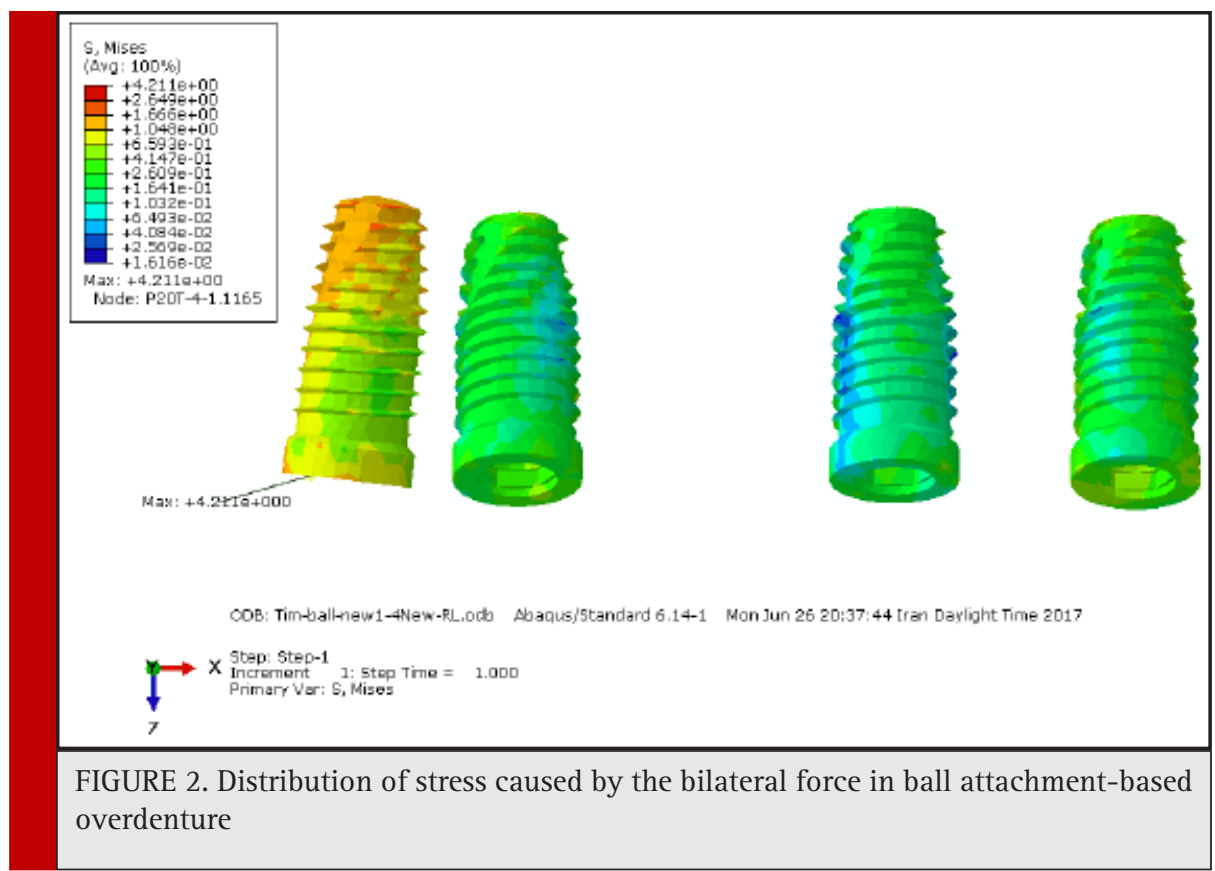




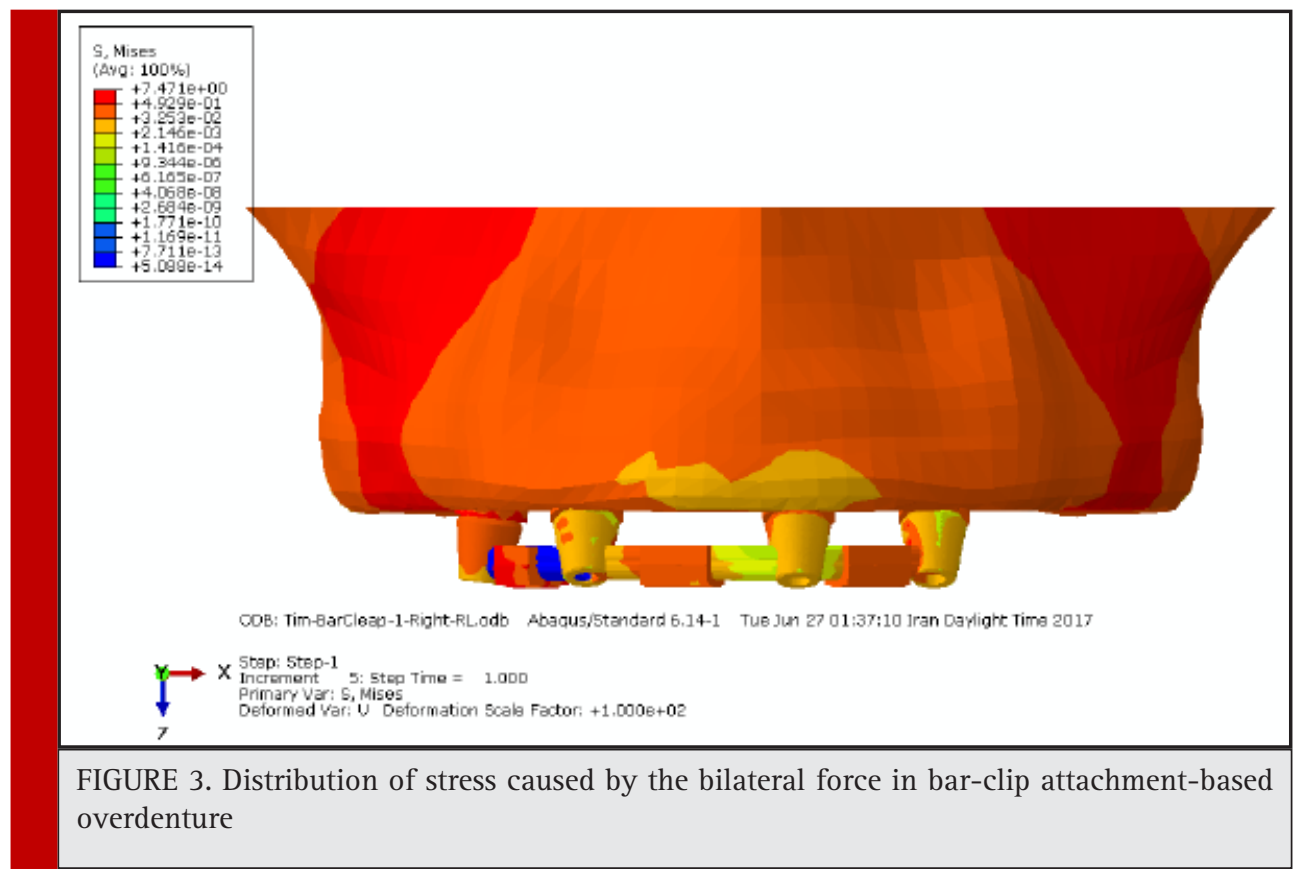

sponge bones did not reach the ultimate bone resistance in any of the treatment designs (Figures 1 to 4).

Among the three different attachment designs studied in this study, the highest bone stress was observed around the implant of the second right premolar area (working) where locator attachment was used. In the present study, the locator attachment was not evaluated using the FEA method. After the locator attachment, the highest stress was observed in the bone around the implant of the second premolar area (working) using the ball attachment and the result was consistent with the result of the study by Chun et al. with the difference that the vertical input force was $150 \mathrm{~N}$ was applied only bilaterally. In the present study, vertical forces were applied unilaterally and bilaterally with the highest concentration of stress in the working side of the bone near the nearest implant to the loading site in both cases.

According to the non-uniformity of force distribution obtained in the study of Mejer et al., the highest the stress was seen in the working side of the bone and

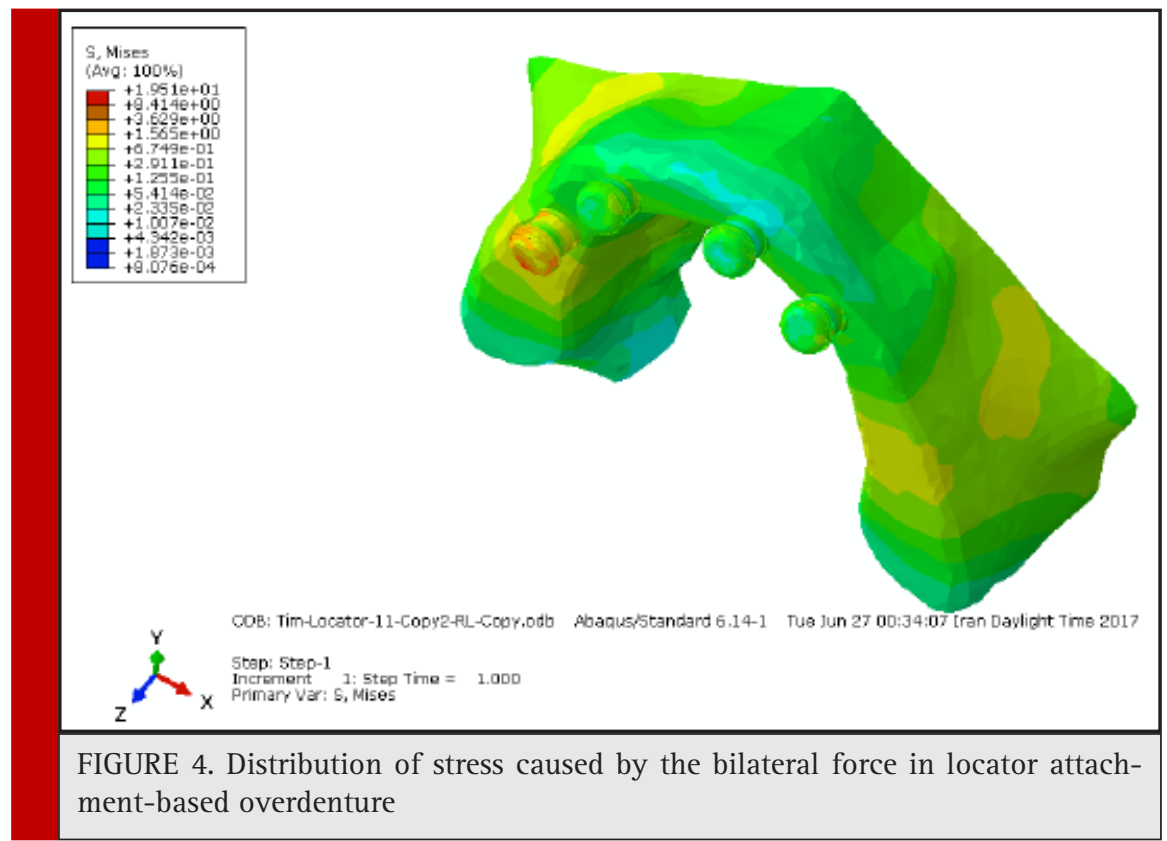


Table 1. Maximum stress in implants in different treatment designs (Mpa) (bilateral force)

\begin{tabular}{|l|c|c|c|l|}
\hline Left central & Tooth Left canin & Tooth right canin & Right second premolar & Treatment plan \\
\hline $0 / 01$ & $0 / 674$ & $0 / 674$ & $1 / 56$ & Locator \\
\hline 0/0071 & $0 / 0071$ & $0 / 0071$ & $0 / 615$ & Ball \\
\hline 0/070 & $0 / 070$ & $0 / 070$ & $1 / 3$ & Bar-clip \\
\hline
\end{tabular}

Table 2. Maximum stress in implants in different treatment designs (MPa) (left force)

\begin{tabular}{|l|c|c|c|l|}
\hline Left central & Tooth Left canin & Tooth right canin & Right second premolar & Treatment plan \\
\hline 0/017 & $0 / 017$ & $0 / 00801$ & $0 / 00801$ & Locator \\
\hline 0/075 & $0 / 2033$ & $0 / 075$ & $0 / 040$ & Ball \\
\hline 0/014 & $0 / 3239$ & $0 / 014$ & $0 / 075$ & Bar-clip \\
\hline
\end{tabular}

Table 3. Maximum stress in implants in different treatment designs (MPa) (right force)

\begin{tabular}{|l|c|c|c|l|} 
Left central & Tooth Left canin & Tooth right canin & Right second premolar & Treatment plan \\
\hline $0 / 0012$ & $0 / 063$ & $0 / 168$ & $0 / 4863$ & Locator \\
\hline $0 / 0031$ & $0 / 127$ & $0 / 127$ & $0 / 3218$ & Ball \\
\hline 0/031 & $0 / 031$ & $0 / 4863$ & $1 / 202$ & Bar-clip \\
\hline
\end{tabular}

Table 4. Maximum stress in bone around implants in different treatment designs (Mpa) (bilateral force)

\begin{tabular}{|l|c|c|c|l|}
\hline Left central & Tooth Left canin & Tooth right canin & Right second premolar & Treatment plan \\
\hline $0 / 067$ & $0 / 067$ & $0 / 067$ & $22 / 87$ & Locator \\
\hline $0 / 0071$ & $0 / 0071$ & $0 / 0071$ & $12 / 88$ & Ball \\
\hline $0 / 0078$ & $0 / 0078$ & $0 / 0078$ & $7 / 486$ & Bar-clip \\
\hline
\end{tabular}

the nearest implant to the force insertion site, and the results confirms the consistency of both studies. According to the results, the lowest concentration of stress in the bone around the implant was observed when loadclip-based overdenture was used, which is inconsistent with the results obtained in the study of Menicucci et al. on two types of ball and bar attachments. They used a vertical $35 \mathrm{~N}$ force on the mandibular overdenture, and the results showed that ball attachment tends to transmit less stress than the bar-clip attachment in the bone around the implant.

In the present study, the vertical force input was investigated in maxilla and the resulting difference requires a review of similar studies in this area. In a

\begin{tabular}{|l|c|c|c|l|}
\hline \multicolumn{5}{|c|}{ Table 5. Maximum stress in the bone around the implants in different treatment designs (MPa) (left force) } \\
\hline Left central & Tooth Left canin & Tooth right canin & Right second premolar & Treatment plan \\
\hline $0 / 170$ & $1 / 477$ & $0 / 170$ & $0 / 3626$ & Locator \\
\hline $0 / 548$ & $0 / 3626$ & $1 / 477$ & $0 / 075$ & Ball \\
\hline $0 / 114$ & $0 / 323$ & $7 / 365$ & $0 / 0403$ & Bar-clip \\
\hline
\end{tabular}

\begin{tabular}{|l|c|c|c|l|}
\hline \multicolumn{4}{|l|}{ Table 6. Maximum stress in the bone around the implants in different treatment designs (MPa) (right force) } \\
\hline Left central & Tooth Left canin & Tooth right canin & Right second premolar & Treatment plan \\
\hline $0 / 168$ & $7 / 486$ & $0 / 450$ & $22 / 87$ & Locator \\
\hline $0 / 809$ & $0 / 809$ & $0 / 809$ & $12 / 88$ & Ball \\
\hline $0 / 0315$ & $0 / 450$ & $0 / 486$ & $7 / 486$ & Bar-clip \\
\hline
\end{tabular}


previous study, locator, ball and bar-clip attachments, respectively, caused the highest amount of stress to the bone around the implant in maxilla. Valentim et al. obtained similar results by investigating Ball \& Bar, Ball and Bar attachments in the mandible by applying a vertical force of $100 \mathrm{~N}$ and found that the highest stress was fed through the Ball type attachment to the bone around the implant. In the present study, the highest level of stress in the bone around the implant was concentrated in the implant neck region, which was completely consistent with the results of the previous studies. In the study of stress in metal parts in ball attachments, the stress concentration occurred in the cervical area of the attachment in the 5th tooth of the right implant area. The stress concentration for the bar-clip attachment was observed between the 5th and 3rd tooth right implants. In the locator attachment, the greatest stress in the housing area of the locator attachment was entered into the right side of the 5th tooth. Compared to the different treatment designs, the stress at the bar-clip attachments was higher than the other two. It is recommended to use the bar-clip treatment design in some cases where reducing stress in the bone around the implant is more important than overdenture stability and stress in the metal parts. If there is no necessity in these cases, you can use the Ball and Locator treatment designs as needed.

The greatest amount of bone stress in all treatment designs was concentrated in the cervical implants in the working side and a few upper threaded implants, and the stress rate didn't reach to the ultimate bone strength in any of the treatment designs, thus, it seems that bone resorption will not occur in any none of the treatment designs. In clinical situations where overdenture is expected to undergo lot of force, it is recommended to use the Bar-Clip treatment design because less stress is transmitted to the bone around the implant. The maximum stress induced in the implant-based overdenture model was observed in the locator attachment, and the implant overdenture supported by the Bar-clip attachment with less stress was the most appropriate design for the present study.

\section{REFERENCES}

Abnet, C.C., Qiao, Y.L., Dawsey, S.M., Dong, Z.W., Taylor, P.R. and Mark, S.D., 2005. Tooth loss is associated with increased risk of total death and death from upper gastrointestinal cancer, heart disease, and stroke in a Chinese population-based cohort. International journal of epidemiology, 34(2), pp.467-474.

Assunção, W.G., Tabata, L.F., Barao, V.A.R. and Rocha, E.P., 2008. Comparison of stress distribution between complete denture and implant-retained overdenture-2D FEA. Journal of oral rehabilitation, 35(10), pp.766-774.
Awad, M.A., Lund, J.P., Shapiro, S.H., Locker, D., Klemetti, E., Chehade, A., Savard, A. and Feine, J.S., 2003. Oral health status and treatment satisfaction with mandibular implant overdentures and conventional dentures: a randomized clinical trial in a senior population. International Journal of Prosthodontics, 16(4).

Baumeister, T., 1978. Standard Handbook for Mechanical Engineer. McGraw-Hill Interamericana.

Berglundh, T., Persson, L. and Klinge, B., 2002. A systematic review of the incidence of biological and technical complications in implant dentistry reported in prospective longitudinal studies of at least 5 years. Journal of clinical periodontology, 29(s3), pp.197-212.

Bilhan, H., Mumcu, E. and Arat, S., 2011. The comparison of marginal bone loss around mandibular overdenture-supporting implants with two different attachment types in a loading period of 36 months. Gerodontology, 28(1), pp.49-57.

Büttel, A.E., Bühler, N.M. and Marinello, C.P., 2009. Locator or ball attachment: a guide for clinical decision making. Schweizer Monatsschrift fur Zahnmedizin= Revue mensuelle suisse d'odonto-stomatologie $=$ Rivista mensile svizzera di odontologia e stomatologia, 119(9), pp.901-918.

Cakir, O., Kazancioglu, H.O., Celik, G., Deger, S. and Ak, G., 2014. Evaluation of the efficacy of mandibular conventional and implant prostheses in a group of Turkish patients: A quality of life study. Journal of Prosthodontics, 23(5), pp.390-396.

Chee, W. and Jivraj, S., 2006. Treatment planning of the edentulous mandible. British dental journal, 201(6), p.337.

Chun, H.J., Park, D.N., Han, C.H., Heo, S.J., Heo, M.S. And Koak, J.Y., 2005. Stress distributions in maxillary bone surrounding overdenture implants with different overdenture attachments. Journal of oral rehabilitation, 32(3), pp.193-205

Cunha, T.R., Della Vecchia, M.P., Regis, R.R., Ribeiro, A.B., Muglia, V.A., Mestriner, W. and De Souza, R.F., 2013. A randomised trial on simplified and conventional methods for complete denture fabrication: masticatory performance and ability. Journal of dentistry, 41(2), pp.133-142.

Dezhdar, S., Fereidoonpoor, N., Mostaghni, E., Jahanpour, F. and Ravanipour, M., 2017. Transition from being OK to NOT OK with tooth loss among a selection of older people in Iran: a qualitative study. Gerodontology, 34(2), pp.215-226.

Dias, R., Moghadam, M., Kuyinu, E. and Jahangiri, L., 2013. Patient satisfaction survey of mandibular two-implantretained overdentures in a predoctoral program. The Journal of prosthetic dentistry, 110(2), pp.76-81.

Dudley, J., 2014. The 2-implant maxillary overdenture: A clinical report. The Journal of prosthetic dentistry, 112(2), pp.104107.

Geerts, G.A., 2017. Neutral zone or conventional mandibular complete dentures: a randomized cross-over trial comparing oral-health related quality of life. Journal of Oral Rehabilitation.

Goiato, M.C., Ribeiro, P.P., Garcia, A.R. and Dos Santos, D.M., 2008. Complete denture masticatory efficiency: a literature 
review. Journal of the California Dental Association, 36(9), pp.683-686.

Jacques, L.B., Moura, M.S., Suedam, V., Souza, E.A.C. and Rubo, J.H., 2009. Effect of cantilever length and framework alloy on the stress distribution of mandibular-cantilevered implant-supported prostheses. Clinical oral implants research, 20(7), pp.737-741.

Locker, D., 1998. Patient-based assessment of the outcomes of implant therapy: a review of the literature. International Journal of Prosthodontics, 11(5).

Lončar, B., 2015. Konfekcijski pričvrsni sustavi pokrovnih proteza nošenih implantatima (Doctoral dissertation, University of Zagreb. School of Dental Medicine. Department of Removable Prosthodontics.).

MacEntee, M.I., 2003. The impact of edentulism on function and quality of life. Implant overdentures as the standard of care for edentulous patients. Chicago: Quintessence International, pp.23-8.

Machado, A.C.M., Cardoso, L., Brandt, W.C., Henriques, G.E.P. and de Arruda Nóbilo, M.A., 2011. Photoelastic analysis of the distribution of stress in different systems of overdentures on osseous-integrated implants. Journal of Craniofacial Surgery, 22(6), pp.2332-2336.

Motta, A.B., Pereira, L.C. and da Cunha, A.R., 2006. Finite element analysis in 2D and 3D models for sound and restored teeth. In 2006 ABAQUS conference. ABAQUS Inc (pp. 329-43).

Payne, A., Walton, J., Alsabeeha, N., Worthington, H.V. and Esposito, M., 2009. Interventions for replacing missing teeth: attachment systems for implant overdentures in edentulous jaws. The Cochrane Library.

Pennington, J. and Parker, S., 2012. Improving quality of life using removable and fixed implant prostheses. Compendium of continuing education in dentistry (Jamesburg, NJ: 1995), 33(4), pp.268-70.

Powers, J.M. and Sakaguchi, R.L., 2006. Impression materials. Craig's Restorative Dental Materials, 12, pp.269-312.

Raghoebar, G.M., Meijer, H.J., Slot, W., Slater, J.J. and Vissink, A., 2014. A systematic review of implant-supported overdentures in the edentulous maxilla, compared to the mandible: how many implants. Eur J Oral Implantol, 7(Suppl 2), pp.S191S201.

Sadowsky, S.J., 2001. Mandibular implant-retained overdentures: a literature review. The Journal of prosthetic dentistry, 86(5), pp.468-473.

Sadowsky, S.J., 2007. Treatment considerations for maxillary implant overdentures: a systematic review. The Journal of prosthetic dentistry, 97(6), pp.340-348.

Semba, R.D., Blaum, C.S., Bartali, B. and Xue, Q.L., 2006. Denture use, malnutrition, frailty, and mortality among older women living in the community. The journal of nutrition, health \&t aging, 10(2), p.161.

Slot, W., Raghoebar, G.M., Vissink, A. and Meijer, H.J., 2013. Maxillary overdentures supported by four or six implants in the anterior region; 1-year results from a randomized controlled trial. Journal of clinical periodontology, 40(3), pp.303-310.

Vogel, R.C., 2007. Implant Overdentures: A New Standard of Care for Edentulous Patients.

Zafiropoulos, G.G. and Hoffman, 0., 2010. Implant-retained dentures for full-arch rehabilitation: a case report comparing fixed and removable restorations. General dentistry, 59(4), pp.e137-43.

Zarb, G.A., Bolender, C.L., Eckert, S.E., Fenton, A.H., Jacob, R.F. and Mericske-Stern, R., 2004. Prosthodontic treatment for edentulous patients. Mosby. 